\title{
Deteksi Plat Nomor Kendaraan Bermotor Berdasarkan Area pada I mage Segmentation
}

\author{
(Licence Vehicles Detection \\ With Area Based on Image Segmentation) \\ Nur Wakhidah \\ Fakultas Teknologi Informasi dan Komunikasi Universitas Semarang
}

\begin{abstract}
Parking system has begun to use the camera to capture images of license plates of motor vehicles. However, shooting is only a database of images only. Human factors can lead to errors of recording the number of motor vehicles and of course this will affect the duration of the service of the existing parking system. Pattern recognition can be used to implement automatic number plate identification is very useful for everyday life, such as parking management, traffic monitoring, ticketing arrangements, and payment of the toll road.
\end{abstract}

Keywords: detection, plat, image, segmentation

\section{PENDAHULUAN}

Saat ini sistem perparkiran yang biasa diterapkan di sebagian besar wilayah Indonesia adalah sistem perparkiran manual dimana pencatatan nomor polisi kendaraan bermotor dilakukan dengan cara memasukkan nomor polisi kendaraan bermotor ke dalam komputer yang kemudian diproses untuk dicetak dan dihitung waktu parkirnya. Beberapa dari sistem perparkiran yang ada sudah mulai menggunakan kamera untuk menangkap gambar dari plat nomor polisi kendaraan bermotor. Namun, pengambilan gambar tersebut hanya sebatas database berupa image saja. Faktor manusia juga bisa menyebabkan kesalahan pencatatan nomor kendaraan bermotor dan tentu saja hal ini akan mempengaruhi lamanya proses pelayanan dari sistem perparkiran yang ada.
Pengenalan pola merupakan pengelompokkan data numerik dan simbolik (termasuk citra) secara otomatis oleh komputer agar suatu objek dalam citra dapat dikenali dan diinterpretasi, yang juga merupakan tahapan selanjutnya atau analisis dari pengolahan citra.

Pengenalan pola dapat dimanfaatkan untuk menerapkan identifikasi plat nomor secara otomatis yang sangat berguna bagi kehidupan sehari-hari, misalnya manajemen tempat parkir, monitoring lalu lintas, pengaturan tiket, dan pembayaran jalan tol.

\section{PERMASALAHAN}

Bagaimana mendeteksi plat nomor mobil berdasarkan region pada image segmentasi dari data gambar (citra) yang diambil dari kamera, seperti yang tampak pada gambar dibawah ini?

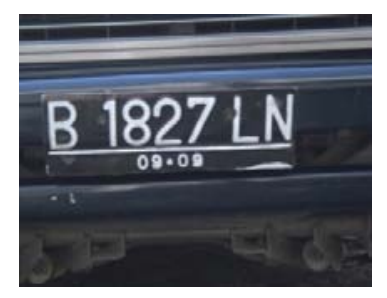

Gambar 1. Data citra 
Dengan batasan masalah bahwa pengambilan gambar dalam keadaan mobil tidak bergerak dan berada dalam jarak antara $100-150 \mathrm{~cm}$.

\section{LANDASAN TEORI}

\subsection{PENGENALAN POLA}

Bertujuan untuk menentukan kelompok kategori pola berdasarkan fitur-fitur atau ciriciri yang dimiliki oleh pola tersebut. Setiap objek tertentu memiliki fitur-fitur tertentu, dengan demikian, pengenalan pola dapat membedakan suatu objek dengan objek yang lain. Suatu aplikasi pengenalan pola bertujuan untuk melakukan proses pengenalan terhadap suatu objek (misalnya citra), salah satu hasilnya adalah mengklasifikasikan objek tersebut dalam kategori tertentu, berdasarkan pola yang dimilikinya. Secara umum, model pengenalan pola dapat digambarkan dalam diagram blok sederhana pada gambar 2 .

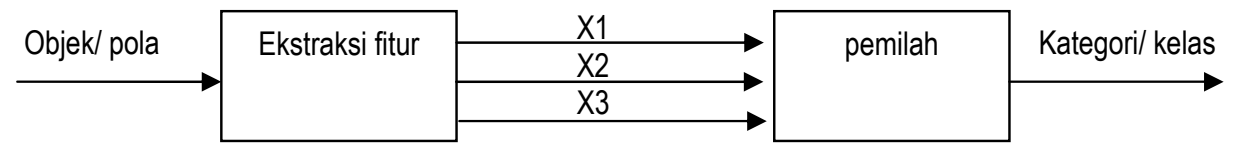

Gambar 2. Model Pengenalan Pola

Berdasarkan gambar 2 diatas, terdapat 2 komponen utama system pengenalan pola yaitu ekstraksi fitur dan pemilah.

Dalam prakteknya, diperlukan prosedur pengambilan keputusan terhadap isi suatu objek gambar 3. Objek dapat berupa teks, citra, audio maupun video. Oleh karena itu system pengenalan pola memerlukan sensor yang berfungsi sebagai sarana untuk memasukkan data ke dalam system pengenalan pola.

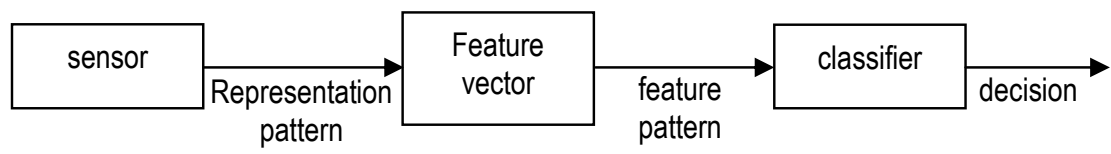

Gambar 3. Prosedur Pengambilan Keputusan

Klasifikasi (classification) dibagi atas supervised classification dan unsupervised classification. Pada supervised classification kelas-kelas diketahui sebelumnya dan data sampel tersedia untuk setiap kelas. Sedangkan pada unsupervised classification kelas-kelas dan atau jumlah kelas tidak diketahui dan hanya mengacu pada data yang akan dikelompokkan.

Untuk membangun system klasifikasi (supervised classification). Sebelumnya system harus memiliki memori atau pengetahuan menyangkut objek yang akan diklasifikasikan. Representasi memori atau pengetahuan ini dapat dibangun dengan mempelajari beberapa objek pelatihan (sampel) dan menyimpannya dalam basis data.

\subsection{Pengertian Pola dan Fitur}

Secara umum, pengertian pola (pattern) dapat dibedakan dengan istilah ciri/ fitur sebagai berikut pola adalah komposit, gabungan atau himpunan dari fitur yang merupakan sifat dari suatu objek. Ciri/ fitur adalah segala jenis aspek pembeda atau ciriciri yang membedakan. Ciri inilah yang digunakan dalam melakukan identifikasi terhadap objek yang dikenali. Oleh karena itu pemilihan fitur sangat menentukan keberhasilan dalam pengenalan pola. 
Ukuran fitur diperoleh dari hasil ekstraksi fitur pada objek. Ukuran fitur bisa berwujud simbolik (misalnya warna) atau numeric (misalnya tinggi). Fitur yang bagus adalah fitur yang memiliki daya pembeda yang tinggi, sehingga pengenalan/ pengelompokan pola berdasarkan fitur yng dapat dilakukan dengan keakuratan yang tinggi. Contoh fitur objek terlihat pada table 1.

Table 1. Contoh Fitur Objek

\begin{tabular}{|l|l|}
\hline \multicolumn{1}{|c|}{ Objek } & \multicolumn{1}{c|}{ Ciril fitur } \\
\hline Huruf & Tinggi, tebal, titik sudut, lengkungan garis, dll \\
\hline Suara & Amplitudo, frekuensi, nada, intonasi, dll \\
\hline Tanda tangan & Panjang, kerumitan, tekanan, dll \\
\hline Sidik jari & Lengkungan, jumlah garis, dll \\
\hline Buah & Bentuk, warna, dll \\
\hline
\end{tabular}

\subsection{Citra (Image)}

Citra dikelompokkan menjadi citra tampak dan citra tak tampak. lihat gambar 4. Contoh citra tampak dalam kehidupan seharihari adalah foto keluarga, lukisan, apa yang tampak di layar monitor. Sedangkan citra tak tampak misalnya gambar dalam file (citra digital), citra yang direpresentasikan dengan fungsi matematis. Agar dapat dilihat manusia, citra tak nampak ini harus dirubah dulu menjadi citra tampak, misalnya dengan menampilkannya dimonitor atau dicetak diatas kertas.

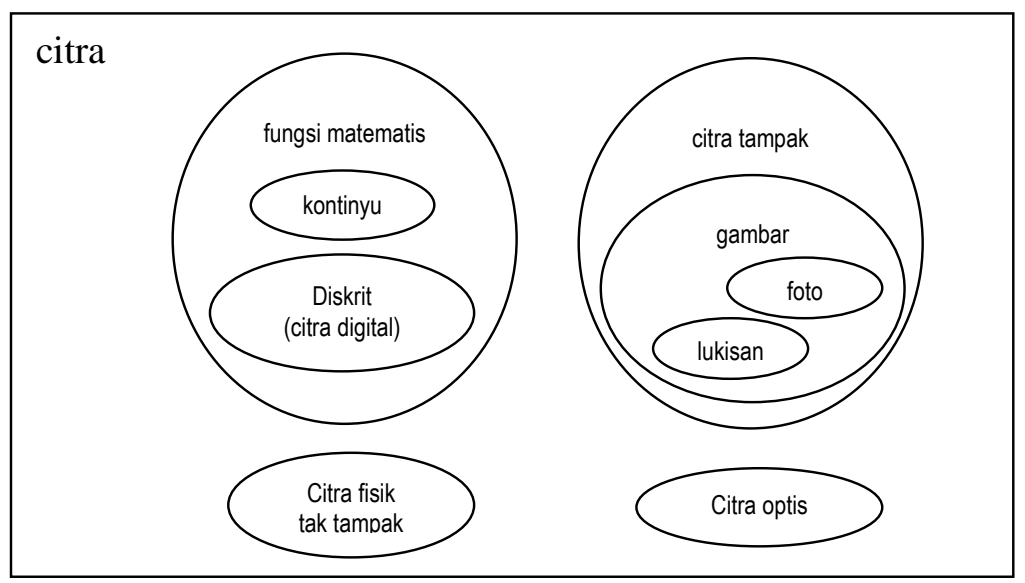

Gambar 4. Pengelompokan Citra

Di antara citra-citra tersebut, hanya citra digital yang dapat diolah menggunakan computer. Jenis citra lain, jika hendak diolah dengan computer, harus diubah terlebih dahulu menjadi citra digital. Proses perubahan citra lain tersebut menjadi citra digital disebut digitasi. Digitasi dapat dilakukan dengan menggunakan alat atau sensor seperti kamera, webcam scanner dan sebagainya.

\subsection{Citra Digital (Digital Image)}

Pada umumnya citra digital berbentuk empat persegi panjang, dengan dimensi ukurannya dinyatakan sebagai lebar $\mathrm{x}$ tinggi (width $\mathrm{x}$ height). Citra digital memiliki koordinat spasial, dengan tingkat kecerahan atau intensitas cahaya (skala keabu-abuan) yang memiliki numeric yang diskrit direpresentasikan dalam bentuk fungsi matematis $f(x, y)$ yang menyatakan intensitas 
cahaya pada titik $(\mathrm{x}, \mathrm{y})$. Dengan demikian citra digital yang lebarnya $\mathrm{M}$ dan tinggi nya $\mathrm{N}$ dan memiliki $L$ derajat keabuan dapat dianggap sebagai fungsi matematis $f(x, y)$ yang menyatakan intensitas cahaya pada titik $(x, y)$ dimana $0 \leq x \leq M, 0 \leq y \leq N$ dan $0 \leq f(x, y) \leq L$.

Citra digital disimpan didalam berkas (file) dengan format tertentu. Format citra yang baku di lingkungan system operasi Microsoft Windows adalah berkas bitmap (bmp). Format bmp mempunyai kelebihan dari segi kualitas gambar apabila citra ditampilkan pada layar monitor, karena citra dalam format BMP umumnya tidak dimampatkan, sehingga tidak ada informasi yang hilang, walaupun akibatnya ukuran berkasnya relative besar.

Citra dalam format bmp ada 3 macam yaitu citra biner, citra berwarna dan hitam putih (grayscale). Citra biner hanya memiliki dua nilai keabuan, 0 dan 1 . Oleh karena itu 1 bit sudah cukup untuk merepresentasikan nilai piksel. Sedangkan citra yang lebih umum adalah citra berwarna. Adapun warna yang terlihat pada gambar dengan format bmp merupakan kombinasi dari tiga warna dasar yaitu Red, Green, dan Blue (RGB). Setiap piksel pada layar monitor disusun oleh tiga komponen warna tersebut. Kombinasi dari ketiga warna tersebut menghasilkan warna yang khas untuk satu piksel bersangkutan.

Salah satu citra warna adalah citra 24 bit, dimana setiap nilai piksel direpresentasikan dengan 24 bit. Setiap piksel langsung menyatakan kombinasi komponen warna RGB.

Masing-masing komponen warna direpresentasikan dengan 8 bit. 8 bit ini merepresentasikan nilai intensitas piksel. Dengan demikian ada sebanyak 28 adalah 256 derajat keabuan (0-255) untuk masingmasing komponen warna. Citra 24 bit disebut juga citra 16 juta warna, karena mampu menghasilkan 224 adalah 16.777.216 kombinasi warna.

System koordinat digunakan untuk menggambarkan posisi suatu citra misalnya pada layar monitor. Pada system koordinat pada gambar 2.4. dibawah ini titik origin ada pada sudut kiri atas dengan sumbu $x$ mendatar ke kanan dan sumbu y menurun ke bawah.

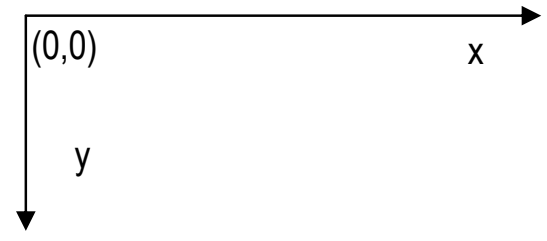

Gambar 5. System Koordinat Pada Layar Monitor

\subsection{Ruang Warna RGB}

Ada beberapa ruang warna misal RGB, HSV, HIS, YIQ dll. Pada model RGB, masingmasing warna dinyatakan dengan 3 komponen warna primer yaitu Red, Green dan Blue. Tiaptiap komponen (RGB) biasanya diwakili oleh 8 bit, sehingga total bit yang diperlukan dalam penyajiaan model warna RGB adalah 24 bit. Dalam model warna 24 bit masing-masing kanal warna (RGB) memiliki 256 bin.

Setiap citra dalam RGB, masingmasing komponen warna RGB mempunyai histogram. Histogram tingkat keabuan adalah suatu fungsi yang menunjukkan jumlah titik yang ada didalam suatu citra untuk setiap tingkat keabuan. Absis (sumbu $x$ ) nya adalah tingkat keabuan, dan ordinat (sumbu y) adalah frekuensi kemunculan atau banyaknya titik dengan nilai keabuan tertentu.

Histogram dapat pula direpresentasikan sebagai vector fitur (fitur veactor) dalam ruang vector berdimensi $n$. Ukuran histogram ditentukan oleh jumlah bit perkanal warna (bin). Jadi histogram citra warna 24 bit memiliki ukuran 256 pada masing-masing kanal warna RGB , sehingga secara keseluruhan terdiri dari 2563 
16.777.216 dimana masing-masing bin dipetakan menuju warna RGB tertentu.

Masing-masing bin mempunyai cacah beberapa kali suatu warna RGB tertentu muncul dalam suatu citra. Distribusi suatu warna RGB tertentu muncul dalam suatu citra dinyatakan dengan :

$$
P_{(R G B)}=\frac{c[R G B]}{T_{c}}
$$

Dimana $c[R G B]=$ cacah dalam suatu bin warna RGB dan Tc menyatakan cacah total yang didapatkan dengan menjumlahkan seluruh cacah bin.

\subsection{Area, Perimeter dan Compactness}

Area suatu objek adalah jumlah piksel penyusun objek tersebut dan unit umum yang digunakan adalah piksel, karena sejumlah piksel tadi membentuk suatu luasan. Area dapat mencerminkan ukuran atau berat objek sesungguhnya. Hal ini berlaku untuk benda pejal dengan bentuk yang hampir seragam, tetapi tidak demikian untuk benda yang berongga.

Perimeter adalah bagian terluar dari suatu objek yang bersebelahan dengan piksel latar belakang. Oleh karena itu, perimeter mempunyai beberapa definisi yang berbeda, namun sebenarnya mempunyai maksud yang sama. Ketiga definisi tersebut adalah:

a. jumlah panjang garis yang memisahkan sepanjang piksel $p$ dan $q$ dimana $p \in S$ dan $q \in S$

b. jumah langkah yang diambil dalam menemukan batas daerah

c. jumlah piksel dari batas daerah

Dari ketiga definisi diatas, definisi ketiga lebih mudah dilakukan dan lebih banyak digunakan. Jadi nilai perimeter dapat dicari dengan menghitung banyaknya piksel yang merupakan piksel-piksel yang berada pada perbatasan dari objek-objek tersebut.

Kekompakan (compactness) suatu objek dapat diukur melalui persamaan berikut:

$$
C=\frac{4 \pi A}{P^{2}}
$$

Dimana $\mathrm{C}, \mathrm{A}$ dan $\mathrm{P}$ masing-masing adalah kekompakan, area dan perimeter. Dengan menganalisis factor bentuk kekompakkan, objek-objek dengan tepi yang rata akan memperlihatkan nilai yang berbeda dengan objek-objek dengan tepi bergerigi. Hal ini dapat digunakan misalnya untuk mengidentifikasi bentuk dan ukuran objek yang sama, tetapi dengan profil tepi yang berbeda. Objek dengan tepi yang rata akan memberikan nilai $C$ sekitar 1 , dan semakin mengecil bila tepinya tidak rata atau membentuk lintasan yang berliku-liku.

\subsection{Pemrograman MATLAB}

MATLAB (Matrix Laboratory) adalah sebuah program untuk analisis dan komputasi numerik, merupakan suatu bahasa pemrograman matematika lanjutan yang dibentuk dengan dasar pemikiran menggunakan sifat dan bentuk matriks.

MATLAB merupakan software yang dikembangkan oleh Mathworks, Inc. dan merupakan software yang paling efisien untuk perhitungan numerik berbasis matriks. Dengan demikian jika di dalam perhitungan kita dapat memformulasikan masalah ke dalam format matriks, maka MATLAB merupakan software terbaik untuk penyelesaian numeriknya.

MATLAB yang merupakan bahasa pemrograman tingkat tinggi berbasis pada matriks sering digunakan untuk teknik komputasi numerik, digunakan untuk menyelesaikan masalah-masalah yang melibatkan operasi matematika elemen, matrik, optimasi, aproksimasi, dan lain-lain. MATLAB banyak digunakan pada :

- Matematika dan Komputasi

- Pengembangan dan Algorithma

- Pemrograman modelig, simulasi dan pembuatan prototipe

- Analisa data, eksplorasi dan visualisasi

- Analisa numerik dan statistik

- Pengembangan aplikasi teknik

\section{PEMBAHASAN}

Untuk menyelesaikan permasalahan tersebut, maka dilakukan beberapa tahap yaitu 


\subsection{Tahap Preprossesing}

Tahap preprossesing adalah proses awal yang dilakukan untuk memudahkan mengenal objek yang dikenali/ diklasifikasikan. Misal memperbaiki kualitas objek, memisahkan objek dari latar belakang, melakukan normalisasi dan lain-lain. Sehingga dalam tahap ini adalah mengkondisikan gambar plat agar dapat ditemukan posisi plat nomor dan memisahkan dari latar belakangnya. adalah:

$$
\text { Langkah-langkah yang dilakukan }
$$

\subsubsection{Resize Image}

Sebuah proses yang dilakukan untuk mengubah sebuah citra digital. Image diresize menjadi 0,6 dari ukuran semula bertujuan untuk mempercepat proses. Proses resize dilakukan dengan menggunakan interpolasi. Dimana interpolasi adalah proses yang digunakan untuk mengestimasi nilai intensitas diantara dua pixel. Sehingga proses ini menghasilkan lokasi píxel yang baru.

Metode interpolasi yang disediakan oleh matlab 7.4.0 (R2007a) adalah Nearestneighbor interpolation, Bilinear interpolation, dan Bicubic interpolation. Teknik interpolasi ini pada dasarnya sama yaitu menghitung bobot rata-rata beberapa pixel terhadap satu titik dan pembobotan didasarkan jarak tiap pixel terhadap titik yang baru.

Perbedaanya adalah sebagai berikut:

- Nearest-neighbor interpolation, pixel baru yang dihasilkan pada berapa nilai itensitas pada titik yang baru dan tidak ada pixel lain yang mempengaruhi.

- Bilinear interpolation, pixel baru adalah hasil dari pembobotan rata-rata antara tiap 2 tetangganya yang terdekat

- Bicubic interpolation, pixel baru adalah hasil dari pembobotan rata-rata antara tiap 4 tetangganya yang terdekat.

Waktu yang dibutuhkan untuk menginterpolasi sebanding dengan tingkat komplektivitas dari proses komputasi yang dilakukan. Metode bilinear memerlukan waktu yang lebih tinggi daripada metode nearestneighbor interpolation, dan metode bicubic memerlukan waktu daripada bilinear. Tetapi metode bicubic lebih akurat daripada metode yang lain. Dalam permasalahan ini akan digunakan teknik bilinear interpolation. Maka penulisan program pada Matlab adalah

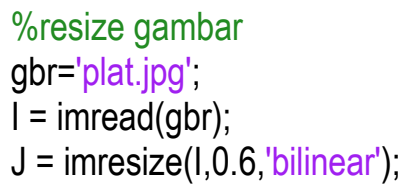

\section{\%figure 1}

figure;

subplot(2,2,1),imshow(I),title('Data : Image'); subplot(2,2,2),imshow(J), title('Resize Image');

\subsubsection{Konversi Warna RGB ke Greyscale} Untuk mengubah warna RGB menjadi grayscale dengan mempertahankan Luminance $(Y)$ dan menghapus Hue (I) dan Saturation (S) harus diawali dengan mengetahui nilai warna merah, hijau dan biru. Pengubahannya adalah dengan menjumlahkan nilai $30 \%$ dari warna merah, $59 \%$ nilai hijau, dan $11 \%$ dari nilai warna biru. Level yang digunakan dapat menggunakan 0.0 sampai $1.0,0$ sampai 255 , atau $0 \%$ sampai $100 \%$. Coding yang dituliskan pada Matlab adalah :

$\mathrm{G}=\operatorname{rgb} 2 \mathrm{gray}(\mathrm{J})$;

subplot(2,2,3),imshow(G), title('Image in Greyscale');

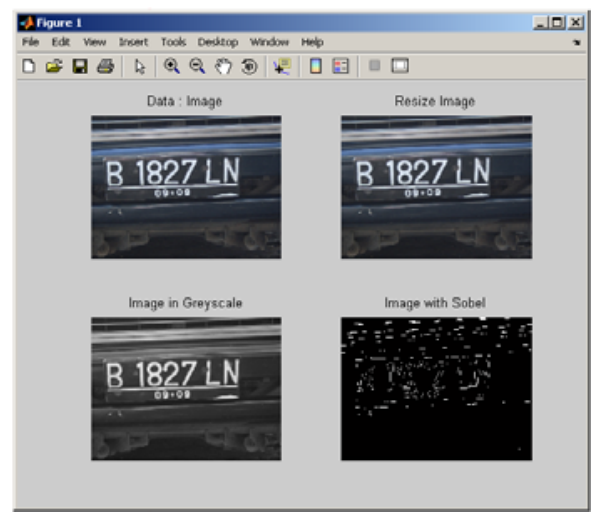

Gambar 6. Preprossesing (Data Image, Resize Image, Greyscale, Sobel) 


\subsubsection{Deteksi Tepi}

Tepi (edge) adalah perubahan nilai intensitas derajat keabuan yang cepat/tiba-tiba (besar) dalam jarak yang singkat. Dimana tujuan deteksi tepi adalah untuk meningkatkan penampakan garis batas suatu daerah atau obyek di dalam citra sehingga dapat menentukan batas antara dua daerah dengan greylevel yang berbeda.

Operator yang dapat digunakan dalam pendeteksian tepi adalah :

- Sobel

- Prewitt

- Canny

- Roberts

- Laplacian of Gaussian

- Zero Cross

Dalam kasus ini akan digunakan operator Sobel. Dimana rumusan pengaturan pixel di sekitar pixel $(x, y)$ adalah:

$$
\left(\begin{array}{ccc}
a_{0} & a_{1} & a_{2} \\
a_{7} & (x, y) & a_{3} \\
a_{6} & a_{5} & a_{4}
\end{array}\right)
$$

Operator Sobel adalah magnitudo dari gradien yang dihitung dengan

$$
M=\sqrt{\left(s x^{2}+s y^{2}\right)}
$$

Turunan parsial dihitung dengan

$$
\begin{aligned}
& s x=\left(a_{2}+c a_{3}+a_{4}\right)-\left(a_{0}+c a_{7}+a_{6}\right) \\
& s y=\left(a_{0}+c a_{1}+a_{2}\right)-\left(a_{6}+c a_{5}+a_{4}\right)
\end{aligned}
$$

dengan konstanta $\mathrm{c}=2$. Dalam bentuk mask, $\mathrm{sx}$ dan sy dinyatakan sebagai:

$$
s x=\left(\begin{array}{ccc}
-1 & 0 & 1 \\
-2 & 0 & 2 \\
-1 & 0 & 1
\end{array}\right) \quad s X=\left(\begin{array}{ccc}
1 & 2 & 1 \\
0 & 0 & 0 \\
-1 & -2 & -1
\end{array}\right)
$$

Arah tepi dihitung dengan:

$$
\alpha(x, y)=\arctan \left(\frac{s y}{s x}\right)
$$

Untuk coding dalam Matlab adalah

bw1=edge(G,'sobel');

subplot(2,2,4),imshow(bw1), title('Image with Sobel');
Menyambung pixel yang mempunyai jarak kurang dari sama dengan 10 pixel.

Image diluaskan area sebesar 10 pixel, sehingga pixel yang mempunyai jarak kurang dari 10 pixel menjadi satu objek. Tujuan dari poses ini adalah untuk menjadikan area plat menjadi satu objek. Dan penulisan programnya adalah

\section{\%figure 2}

$\%$ coba imclose

se = strel('disk',10);

closebw = imclose $($ bw1,se);

figure, subplot(2,2,1), imshow(closebw), title('Menggandeng Pixel (10)');

\subsubsection{Menghilangkan noise}

Dengan menghilangkan luasan yang mempunyai luasan kurang dari 10 pixel, sehingga luasan yang tidak digunakan akan dibersihkan. Untuk codingnya adalah

$\%$ menghilangkan noise (10 pixel) bwvv=bwareaopen(closebw, 10); subplot(2,2,2),imshow(bwvv), title('Menghilangkan noise');

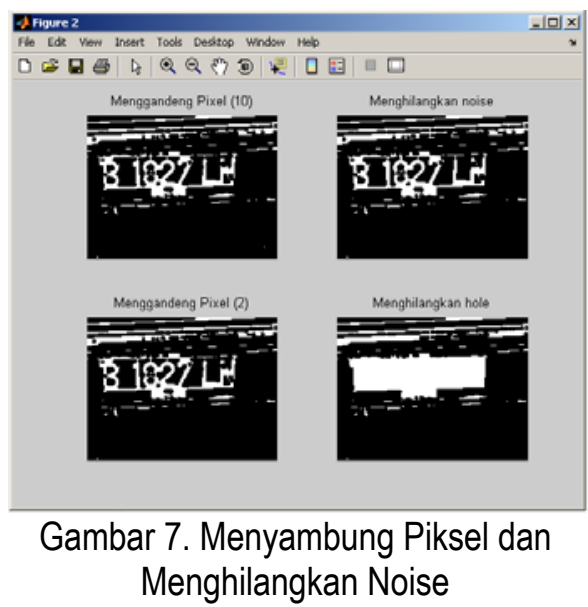

\subsection{Tahap Segmentasi Plat}

Dalam tahap ini merupakan tahap pemecahan image kedalam obyek-obyek yang terkandung didalamnya yang dapat menjadi sarana untuk automated image analysis, misal untuk pengenalan obyek-obyek dalam image. Segmentasi dapat dilakukan berdasar pada kemiripan (similarity), dimana image dibagi 
berdasar kemiripan gray level. Teknik yang termasuk dalam kelompok ini adalah thresholding, region growing, region splitting, region merging. Dalam aplikasi yang akan dikerjakan maka akan dilakukan perhitungan luas suatu wilayah untuk membedakan plat nomor dan latar belakangnya.

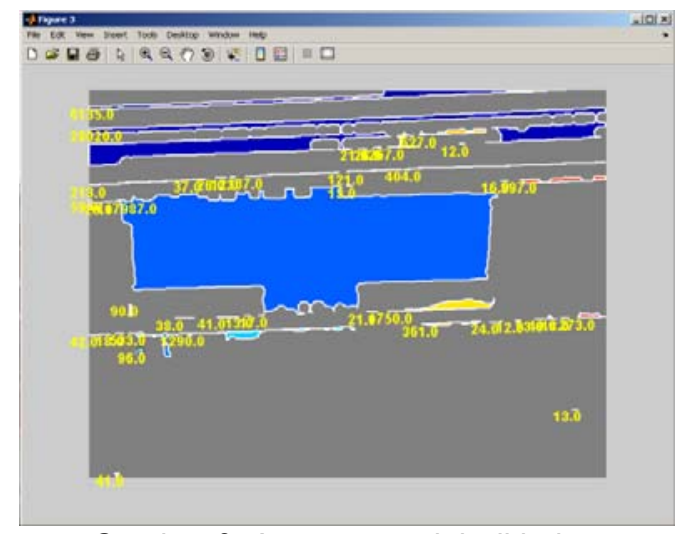

Gambar 8. Area yang telah di index dan dicari luasnya

Mencari luas area yang telah diindex

Masing-masing kandidat dicari luasannya, kandidat yang terpilih dicari koordinatnya, dan informasi koordinat digunakan untuk mencrop image yang hanya terdapat informasi plat nomor.

Tahapan segmentasi plat adalah sebagai berikut:

- Mengindex semua objek yang terdapat pada image

- Mencari luas masing-masing objek

- Mencari objek yang mempunyai luas sebagai plat nomor

Tujuan dari proses ini adalah untuk mengekstrak plat nomor dari gambar yang diambil. Output dari proses ini adalah gambar plat nomor yang tepat pada plat nomornya. Feature extraction menggunakan moment, didefinisikan dengan:

$$
M_{p q}=\int_{-\infty}^{\infty} \int_{-\infty}^{\infty} x^{p} y^{q} f(x, y) d x d y
$$

Dimana $\mathrm{N}=\mathrm{p}+\mathrm{q}$

Range integrasi $x \in(-1,1)$ dan $y \in(-1,1)$ untuk menghindari divergensi maka dicari pusat koordinat, dimana luasan mempunyai panjang
$2 a$ untuk sumbu $x$ dan $2 b$ untuk sumbu $y$. Momen pusat didefinisikan dengan:

$$
M_{p q}=\int_{-\infty}^{\infty} \int_{-\infty}^{\infty}(x-x)^{i}(y-y)^{j} f(x, y) d x d y
$$

Dimana $(x, y)$ adalah pusat dari $f(x, y)$.
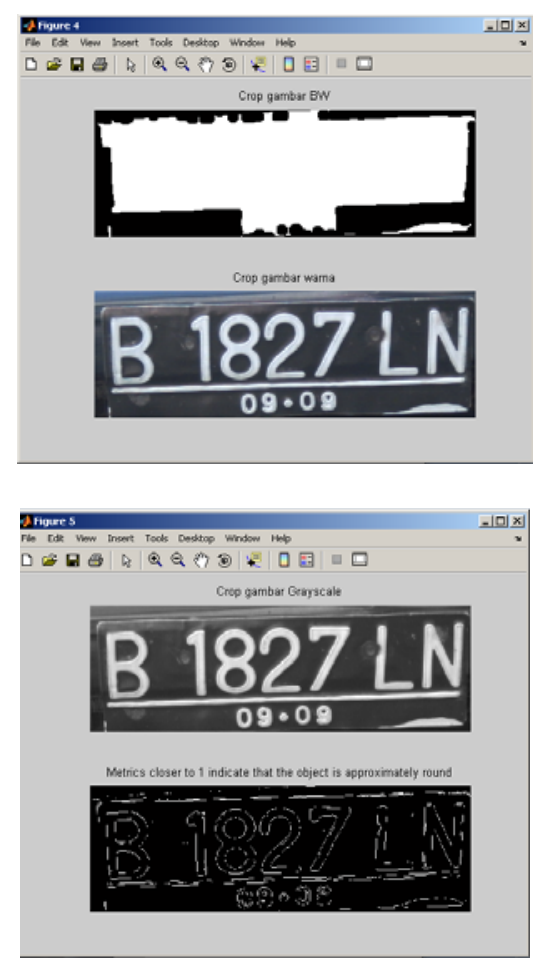

Gambar 9. Hasil gambar plat nomor

\section{KESIMPULAN}

Dari uraian diatas dapat ditarik beberapa kesimpulan, yaitu:

- Tahap preprossesing merupakan tahap yang dapat memudahkan untuk mengenali objek yang akan dikenali/ diklasifikasikan.

- Resize Image mampu mempercepat proses dengan teknik interpolasinya.

- Deteksi Tepi dengan operator sobel memberikan hasil yang lebih baik daripada operator lainnya.

- Luas area maksimum mampu mengidentifikasi plat nomor mobil setelah penyambungan piksel, menghilangkan noise, menghilangkan hole dan pengindeksan setiap objek. 


\section{DAFTAR PUSTAKA}

Abdullah. Klasifikasi Buah-buahan berdasarkan Warna dan Bentuk. UGM Jogjakarta.

Gunaidi Abdia Away, MATLAB Programming, Informatika, 2006.

Munir, Rinaldi. Pengolahan Citra Digital dengan Pendekatan Algoritmik. Penerbit Informatika. 2004.

Ozbay, Ercelebi. Automatic Vechicle Identification by Plat Recognition. Transactions on Engineering, Computing and Technology V9 November ISSN 1305-5313. 2005.

Resmana Lim, Lukman Vendy W., Kartika Gunadi, Sistem Pengenalan Plat Nomor Mobil Dengan Metode Principal Components Analysis, Jurnal Teknik Elektro Universitas Kristen Petra Mar 2003 / Vol 3 / No

Ron, Erez. A Real-Time Vechicle Licence Plate Recognition (LPR) System. Ollendorf Research Center. 2002.

Sergios Theodoridis. Pattern Recognition. Elsevier Academic Press. 2003 